\title{
ALIENAÇÃO PARENTAL - MEIOS DE PREVENÇÃO ADOTADOS PELO ESTADO DEMOCRÁTICO DE DIREITO
}

\author{
Priscila Fernandes Santana ${ }^{1}$ \\ Ana Maria Viola de Sousa ${ }^{2}$ \\ Maurício Martins Alves ${ }^{3}$
}

Resumo: Diante da quebra da unidade familiar, uma das primeiras vítimas são as crianças e adolescentes. Nesta situação, é comum a ocorrência de Alienação Parental, com a tentativa de um cônjuge afastar a criança do outro. O Estado Democrático de Direito, ao atuar na defesa de garantias fundamentais, tem papel relevante na proteção do direito fundamental de convivência familiar e comunitária garantidos a criança e adolescente. Com base nas leis 12.318/2010 e 13.058/2014, bem como jurisprudência e doutrina pertinente, este artigo defende que a guarda compartilhada atua como um mecanismo com força preventiva enquanto a lei sobre alienação parental tem por foco atuar em situações em que já existem indícios de ocorrência de alienação parental - um papel, portanto, mais coativo que preventivo.

Palavras-chave: Alienação Parental; Lei 12.318/2010; Lei 13.058/2014; Prevenção da Alienação Parental; Direito Fundamental de Convivência Familiar.

\footnotetext{
${ }^{1}$ Faculdade de Direito/Universidade do Vale do Paraíba, Brasil. E-mail: priscilafersantana@gmail.com.

2 Faculdade de Direito/Universidade do Vale do Paraíba, Brasil. E-mail: anaviola@aasp.org.br.

${ }^{3}$ Faculdade de Direito/Universidade do Vale do Paraíba, Brasil. E-mail: mmalves@univap.br.
} 